\title{
Physicochemical Peculiarities of Iron Porphyrin - Containing Electrodes in Catalase - and Peroxidase - Type Biomimetic Sensors
}

\author{
T.M.Nagiev \\ Institute of Chemical Problems, National Academy of Sciences of Azerbaijan, Baku, \\ Azerbaijan
}

\section{Introduction}

High sensitivity and substrate specificity of sensors based on biological systems make them irreplaceable as applied measuring devices. Unfortunately, their high sensitivity to environmental impacts, short operation time and high price are the main disadvantages of the biological systems. If the active component of biosensors (biopolymers) is replaced by their chemical analogs, i.e. biomimics which are now being developed in the framework of mimetic catalysis [1], the majority of these and other disadvantages can be eliminated.

Biomimetic analogs of existing enzymatic biosensors have been designed with broader functional abilities using inorganic biomimics, which is one of the strategic directions in the branch of super-sensitive analytical systems. The development of model systems is the only means of succeeding in this direction. Following achievements in mimetic catalysis, biomimetic electrodes of the catalase, peroxidase and monooxygenase type have been effectively designed [2].

At present, enzymatic and enzyme-based biosensor methods [3,4] are widely employed for qualitative and quantitative determinations of lower aliphatic alcohols, in particular, methanol-ethanol mixtures. Biosensors have some obvious advantages: preliminary separation of the sample components is not required; they are highly selective and sensitive; the determinations with their use are fast and do not require complicated apparatus; and they are economical. Sensors based on biological materials (enzymes, cells, tissues, antibodies, receptors, nucleic acids, etc.) have, however, some substantial disadvantages, which, as a rule, restrict their practical applications. These are high sensitivity to the action of the environment, short service time, high cost, the occasional application of complex enzymatic systems, multistep determinations, and some others.

Advances in the field of mimetic catalysis allow synthesis of the biomimetic analogues of corresponding enzymes. Their use in sensors will avoid many of the drawbacks mentioned above.

In this work, we used, as an example, a model peroxidase reaction of oxidation of ethanol into acetaldehyde in the electrochemical regime to elaborate the basic principles of functioning of peroxidase-mimetic sensor devices.

The phenomenon of $\mathrm{H}_{2} \mathrm{O}_{2}$ synthesis as an intermediate product of substrate biooxidation with the participation of many oxidases has formed the foundation for the creation and development of many biosensors possessing immobilized peroxidase as the active substance [5]. 
In general, electrochemically realized biological processes, in which the central place is devoted to $\mathrm{H}_{2} \mathrm{O}_{2}$ synthesis and dissociation reactions, can be presented as follows:

$$
\begin{aligned}
& \mathrm{S} \text { (glucose, amino acids) }+\mathrm{O}_{2} \stackrel{\substack{\text { oxidase } \\
\downarrow}}{\longrightarrow} \mathrm{S}^{\prime}+\mathrm{H}_{2} \mathrm{O}_{3} \\
& \mathrm{H}_{2} \mathrm{O}_{2} \underset{\begin{array}{c}
\uparrow \\
\text { peroxidase }
\end{array}}{\longrightarrow} \mathrm{H}_{2} \mathrm{O}+2 \bar{e}
\end{aligned}
$$

As a rule, the combined immobilization of oxidase and peroxidase on the electrode allows the determination of metabolite (S) concentration, even if negligibly small.

Additional sufficient capabilities also occur as a result of the chemical conjugation mechanism, on which the overwhelming majority of enzymatic reactions are based. There is a firm belief that, in principle, a sequence of conjugated chemical processes can be selected for any reagent, starting from the substance to be detected and ending with an active product of enzymatic reaction. To put it another way, the corresponding enzymatic electrode may always be prepared.

The need to develop concise methods for determining the concentration of $\mathrm{C}_{2} \mathrm{H}_{5} \mathrm{OH}$ in aqueous solutions arises from the requirements imposed by the quality control of alcohol drinks.

Another reason for developing these sensors is for detecting microquantities of $\mathrm{C}_{2} \mathrm{H}_{5} \mathrm{OH}$ in aqueous solutions of various origins.

The authors devoted their investigations to the development of a peroxidase-biomimetic sensor for determining trace quantities of ethyl alcohol in various solutions. In all tests the reaction system represented a mixture of microamounts of hydrogen peroxide and ethyl alcohol in an aqueous medium. The task was to determine the effect of the $\mathrm{H}_{2} \mathrm{O}_{2}: \mathrm{C}_{2} \mathrm{H}_{5} \mathrm{OH}$ ratio on the detection ability of the biomimetic electrode.

Figure 1. shows an electrochemical system - a model of a catalase-biomimetic sensor, consisting of the reference electrode $\left(\mathrm{Ag} / \mathrm{AlCl} / \mathrm{Cl}^{-}\right)$and biomimetic electrode. In this system, the electrochemical potential changed as a result of mimetic electrode interaction with $\mathrm{H}_{2} \mathrm{O}_{2}$ injected into the system. Initially, the system potential is measured in twice distilled water (the background solution) and then, as a definite amount of $\mathrm{H}_{2} \mathrm{O}_{2}$ is added, a change of aqueous $\mathrm{H}_{2} \mathrm{O}_{2}$ potential is observed.

\section{Experimental, results and discussion}

Biomimetic electrode was prepared according to two techniques:

1. inorganic biomimic-catalase adhesion to aluminum foil;

2. based on the active fragment of catalase (the most complicated way to obtain the working element of biomimetic sensor) [6].

A biomimetic sensor was created with electrodes from aluminum wire ( $2 \mathrm{~mm}$ thick) and aluminum foil (size $20 \times 10 \times 1 \mathrm{~mm}$ ), to which the working element was applied by two methods:

1. on an adhesive covering the electrode with a thin layer;

2. mixed with adhesive.

In order to obtain a fragment of catalase, it was immobilized by adsorption on various organic and inorganic carriers (such as aluminum oxide, diasorb DEAE, agarose), with farther trypsine treatment. Aluminum wire or foil was used as the electrode. Such electrodes 


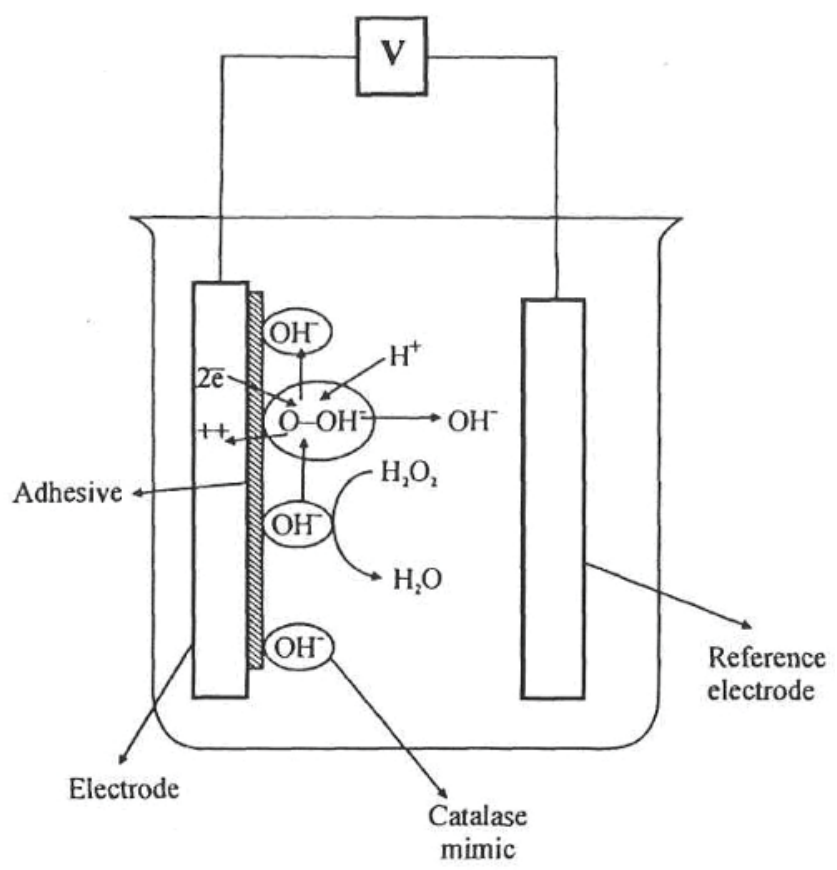

Fig. 1. Catalase-mimetic electrochemical cell.

were selected because of their low price and inertness in relation to hydrogen peroxide. The binding agent between the electrode and biomimic was Pattex adhesive and 7.5\% polyacrylamide gel.

The electrochemical system consisting of a biomimetic selector of catalase or peroxidase type, which was part of the electrode, allowed us to determine the low concentrations of $\mathrm{H}_{2} \mathrm{O}_{2}$ and $\mathrm{C}_{2} \mathrm{H}_{5} \mathrm{OH}$ in aqueous solutions at $22^{\circ} \mathrm{C}$. This formed the basis for inexpensive and easily handled potentiometric biomimetic sensors.

Inorganic mimic of catalase was prepared according to the well-known technique $[1,2]$. Partly purified catalase of human blood erythrocytes and trypsine (Sigma Company) were used for the catalase sources.

The change of electrode potential (E) of the catalase reaction with time was measured by a voltmeter. $\mathrm{pH}$ and $\mathrm{E}$ values for aqueous hydrogen peroxide were determined simultaneously for possible correlations between $\mathrm{pH}$ metric and potentiometric results of enzymatic activity of catalase-biomimetic sensors. The electrochemical unit was also equipped with a magnetic mixer.

For the purpose of determining low hydrogen peroxide concentrations, the authors have designed the most cost-effective and simple to use potentiometric-biomimetic sensors based on immobilized catalase mimics. These sensors possess high hydrodynamic properties and the fastest speed of response. Figure 8.3 shows experimental data on catalase activity of biomimetic electrode in $0.03 \%$ aqueous $\mathrm{H}_{2} \mathrm{O}_{2}$. For the sake of comparison, catalase activities of aluminum electrode and aluminum electrode with applied adhesive are also shown. 
Peroxidase mimetic, like its catalase analogue, consists of two parts: the active part and the support. The support is a neutral activated aluminum oxide onto which an active site (hematin with $8.6 \mathrm{wt} \%$ iron, Sigma) is deposited. The biomimetic is synthesized by the known procedure.

The biomimetic sensors $[7,8]$ on the basis of catalase and peroxidase bioimitators for determining ultralow concentrations of $\mathrm{H}_{2} \mathrm{O}_{2}$ and $\mathrm{C}_{2} \mathrm{H}_{5} \mathrm{OH}$ are still at the development stage because of disadvantages that hinder their practical applications. For example, the presence of glue material [7] on the surface of an electrode led to quick deactivation of the biomimetic selector because of protoporphyrin's insufficient stability to the oxidant $\left(\mathrm{H}_{2} \mathrm{O}_{2}\right)$ and its intermediates and decomposition of the biomimetic electrode.

It is important to develop more active and stable biomimetic iron porphyrin electrodes free of the above drawbacks: to create and study the physicochemical features of new variants of catalase - and peroxidase-type iron porphyrin electrodes to determine ultralow concentrations of $\mathrm{H}_{2} \mathrm{O}_{2}$ and $\mathrm{C}_{2} \mathrm{H}_{5} \mathrm{OH}$ in aqueous solutions.

The oxide coating $\left(\mathrm{A}_{2} \mathrm{O}_{3}\right)$ of the aluminum electrode was prepared by electrochemical and chemical methods [9]. Iron porhyrin derivatives were deposited by adsorption on the coatings. In the biomimetic selector, the matrix was the oxidized surface of the aluminum electrode $\left(\mathrm{A}_{2} \mathrm{O}_{3}\right)$. This was a new design, which allowed us to avoid using glue materials and increased the activity and stability of the biomimetic selector.

\section{Catalase biomimetic sensors}

In all three cases ( $\mathrm{Al}, \mathrm{Al}$ with applied adhesive and biomimetic electrode), as observed from Figure 2., the presence of hydrogen peroxide in the system causes an initial sharp increase of the system potential. This is most likely associated with the formation of a new surface layer at the electrode-solution interface. Some time later an equilibrium surface layer is formed and the potential at Al-solution and $\mathrm{Al}$-adhesive-solution barely changes. Refracto-metric analysis shows that $\mathrm{Al}$ does not cause dissociation of $\mathrm{H}_{2} \mathrm{O}_{2}$ at low concentration of the latter, whereas electrochemical potential in biomimetic electrode- $\mathrm{H}_{2} \mathrm{O}_{2}-\mathrm{Cl} \sim-\mathrm{AgCl}-\mathrm{Ag}$ system continues changing to almost full $\mathrm{H}_{2} \mathrm{O}_{2}$ dissociation (Figure 1). Dissociation of $\mathrm{H}_{2} \mathrm{O}_{2}$ was tested by solution titration with potassium permanganate.

According to the author's ideas and experiments, the following reactions are implemented in electrochemical system:

Catalase reaction

$$
2 \mathrm{H}_{2} \mathrm{O}_{2} \stackrel{\text { biomimic }}{\longrightarrow} 2 \mathrm{H}_{2} \mathrm{O}+\mathrm{O}_{2}
$$

Electrochemical reaction

$$
\mathrm{O}_{2}+4 \bar{e}+2 \mathrm{H}^{+} \stackrel{\text { electrode }}{\longrightarrow} 2 \mathrm{OH}^{-}
$$

It is common knowledge that hydrogen peroxide is a soft dibasic acid. Therefore, catalase activity of biomimetic electrodes may change the $\mathrm{pH}$ of the $\mathrm{H}_{2} \mathrm{O}_{2}$ solution by both reactions (1) and (2). If these reactions take place on the biomimetic electrode, at the end of the process the $\mathrm{pH}$ of the solution will equal the $\mathrm{pH}$ of the distilled water. 


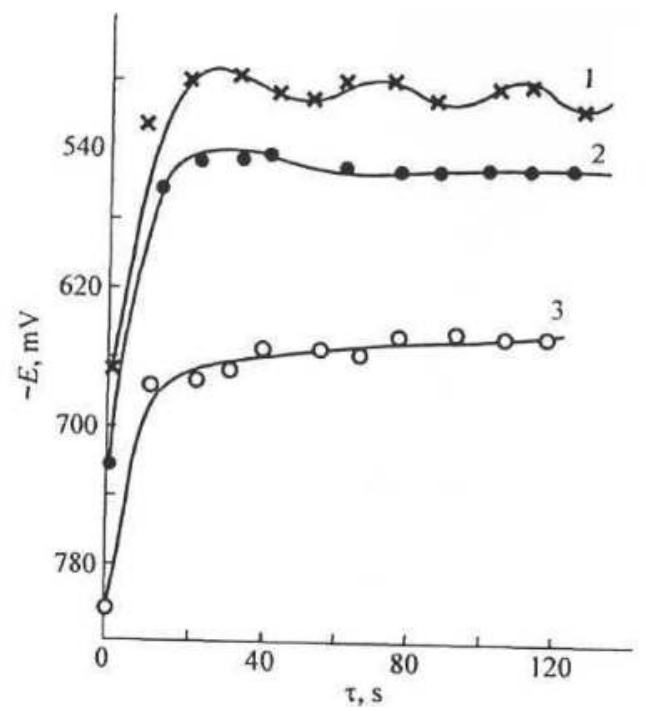

Fig. 2. Time dependence of electrochemical potential in the system. $T=20^{\circ} \mathrm{C} 003$ wt $\% \mathrm{H}, 0$ (1: biomimetic electrode; 2: aluminum electrode; 3 : aluminum electrode with applied adhesive)

For the purpose of determining $\mathrm{H}_{2} \mathrm{O}_{2}$ dissociation mechanism on the electrode the authors followed up the $\mathrm{pH}$ variation dynamics in the system until complete hydrogen peroxide dissociation. Some time after the start of the process the course of the curve in Figure 3 indicates a $\mathrm{pH}$ higher than for redistilled water (background solution) approaching 7 . Titration by $\mathrm{KMnO}_{4}$ showed that a trace concentration of hydrogen peroxide below the sensitivity of biomimetic electrode still remained in the solution.

The fact that the $\mathrm{pH}$ of the reaction mixture exceeds the value for redistilled water testifies to the implementation of both reactions (1) and (2) in the system. Note that in the absence of reaction (2) and full $\mathrm{H}_{2} \mathrm{O}_{2}$ dissociation, the $\mathrm{pH}$ observed for the solution must correspond to the $\mathrm{pH}$ of the redistilled water (6.2).

These data present an experimental proof of proceses (1) and (2) run on the biomimetic electrode and the consequences:

1. A definite quantity of oxygen molecules accumulated on the surface of the biomimetic electrode (catalase reaction) must diffuse to the volume of the adhesive layer, toward the electrode surface. Hence, the specific requirements to the adhesive follow: on the one hand, it must provide strong enough adhesion of a mimic to electrode; on the other hand, it must possess low oxygen adsorption ability.

2. The adhesive must be highly inert in the catalase reaction.

3. $\mathrm{OH} \sim$ anions, formed in electrode reaction (2), must display higher adsorption ability to the adhesive.

4. The exclusive role of surface oxygen in electrochemical reaction (2). 


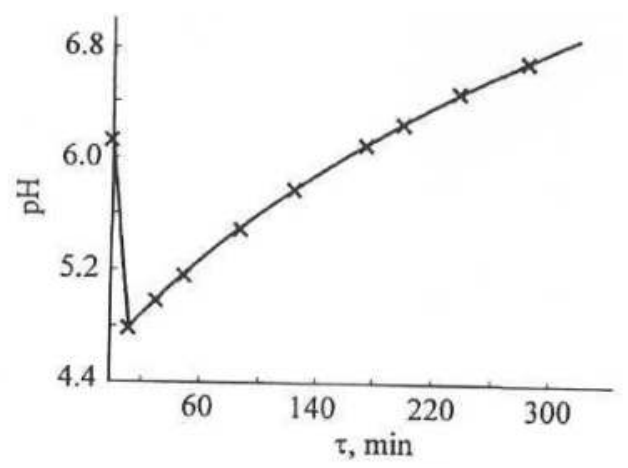

Fig. 3. Time dependence of $\mathrm{pH}$ for aqueous $\mathrm{H}_{2} \mathrm{O}_{2}$ dissociation. $T=20^{\circ} \mathrm{C}, 0.01 \mathrm{wt} . \% \mathrm{H}_{2} \mathrm{O}_{2}$.

The additional experimental proof of the last statement is given by data in Figure 4. Curve (a) shows the change of $\mathrm{pH}$ and potential in the 'mimetic electrode- $\mathrm{H}_{2} \mathrm{O}_{2}-\mathrm{CI}-\mathrm{AgCl}-\mathrm{Ag}$ ' system. Curve (b) shows the results of tests carried out for the mimic applied on the electrode surface. According to these data, the potential abruptly decreases in the system, whereas curve (a) indicates its increase.

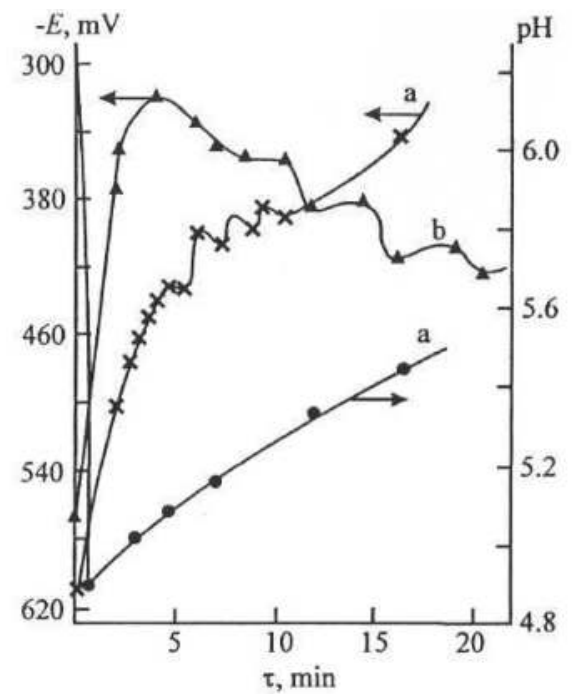

Fig. 4. Time dependence of electrochemical potential in the system and aqueous $\mathrm{H}_{2} \mathrm{O}_{2} \mathrm{pH}$, $T=20^{\circ} \mathrm{C}, 0.01 \mathrm{wt} . \% \mathrm{H}_{2} \mathrm{O}_{2}$ (a: biomimic is adhered to aluminum foil; b: biomimic is present in aqueous $\mathrm{H}_{2} \mathrm{O}_{2}$ ). 
With regard to the above, of special interest are test results for unmixed system (in all other experiments the system was mixed by a magnet mixer). It turns out that part of the molecular oxygen synthesized in the catalase reaction (1) releases from the solid, and forms a gas 'cover' around the mimetic electrode in the interface layer between the solid and the reaction mixture. This circumstance will decelerate $\mathrm{H}_{2} \mathrm{O}_{2}$ diffusion to the biomimetic electrode and decrease the rate of the catalase reaction (8.1), hence promoting electric potential drop. Most of these hindrances can be eliminated by mixing the reaction system. The efficiency of the system mixing is illustrated by data in Fig. 5 .

Although mixing of the solution reduces the diffusion effect on the course of the catalase reaction, a special experiment must be set up to determine the predominance of one of two possible limitations of diffusion and kinetic origin. For this purpose, knowing that the diffusion rate is almost independent of temperature in the system and the chemical reaction rate increases with temperature by $2-A$ times for every $10 \mathrm{~K}$, the temperature influence on the change of potential and $\mathrm{pH}$ in the system was studied. The results of the experiments are presented in Figure 6 . The $\mathrm{pH}$ curves are practically unchanged, although the temperature of the mixture was twice increased. Such regularity is typical of reactions proceeding under diffusion complication conditions, where the catalase reaction rate is limited by diffusion (i.e. depends on $\mathrm{H}_{2} \mathrm{O}_{2}$ delivery to and elimination from the mimetic electrode), but not by kinetics of the catalase reaction. Apparently, electrochemical indices deteriorate as a consequence of an increase in the molecular oxygen desorption rate in the volume which reduces the rate of electrochemical reaction (2). It is also probable that temperature causes any other effect on the physical conditions of the electrode.

In all Figures electrochemical potentials possess clear maxima and minima. Such curve shapes conform to the shape for catalase and electrochemical reactions in the diffusion zone of the system. As mentioned above, molecular oxygen accumulated on the surface of the mimetic electrode during catalase reaction (1) diffuses through the adhesive and mimic layers to the electrode surface, where it is activated and interacts with $\mathrm{H}^{+}$. Anions $\mathrm{OH}^{-}$ formed in this process may set the electrode surface free for the next portion of oxygen by diffusion only. Thus, the rate of electrochemical reaction (2) will be defined by the ratio of the rates of molecular oxygen diffusion to the electrode surface and reverse diffusion of $\mathrm{OH}^{-}$ anions from the surface.

The maxima observed on $E$ curves correspond to the highest rates of electrochemical reaction (2), which are functions of $\mathrm{O}_{2}$ concentration on the electrode, testifying to its highest values under current conditions. During reaction (2) the $\mathrm{O}_{2}$ concentration decreases and the rate of electrochemical reaction (2) is reduced simultaneously. It begins increasing as soon as a new portion of molecular oxygen reaches the electrode surface, set free from $\mathrm{OH}^{-}$anions. Finally, this catalytic process connected to diffusion events will have a sinusoidal shape until $\mathrm{H}_{2} \mathrm{O}_{2}$ is fully dissociated, and the reaction is terminated.

Based on the analysis of the obtained experimental regularities of the electrochemical process, it may be fundamentally concluded that the process at electrode displays a selloscillation mechanism. Obviously, self-oscillations happen due to internal diffusion of the surface components of the mimetic electrode, which is not affected by solution mixing intensity. Mixing causes a strong influence on the external diffusion and $\mathrm{OH} \sim$ anion drainage from the interface layer.

Biomimetic sensors, prepared from catalase adsorbed on diasorb and $\mathrm{A}_{2} \mathrm{O}_{3}$, treated with trypsine and adhered to an aluminum electrode surface using $7.5 \%$ polyacrylamide gel of Pattex adhesive, were found to be the most effective sensors among appliances of this type 


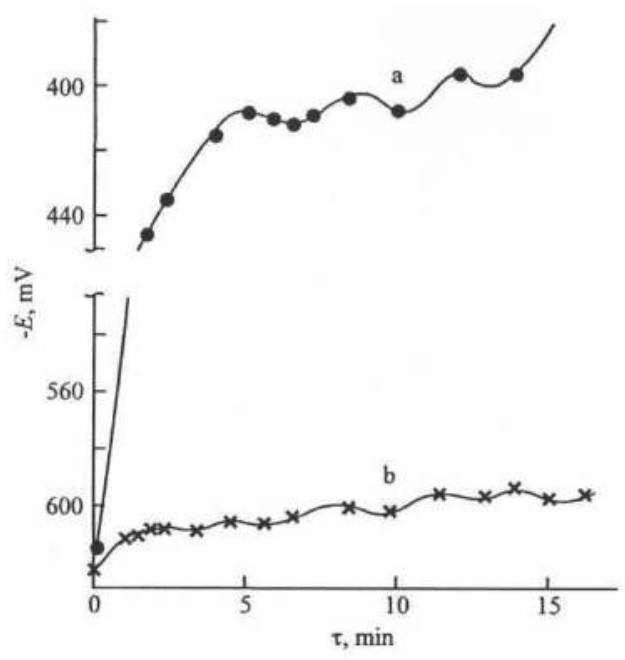

Fig. 5. The mixing effect on the change of electric potential in the system. $T-20^{\circ} \mathrm{C}, 0.01$ wt. $\% \mathrm{H}_{2} \mathrm{O}_{2}$ (a: mixed system; b: without mixing).

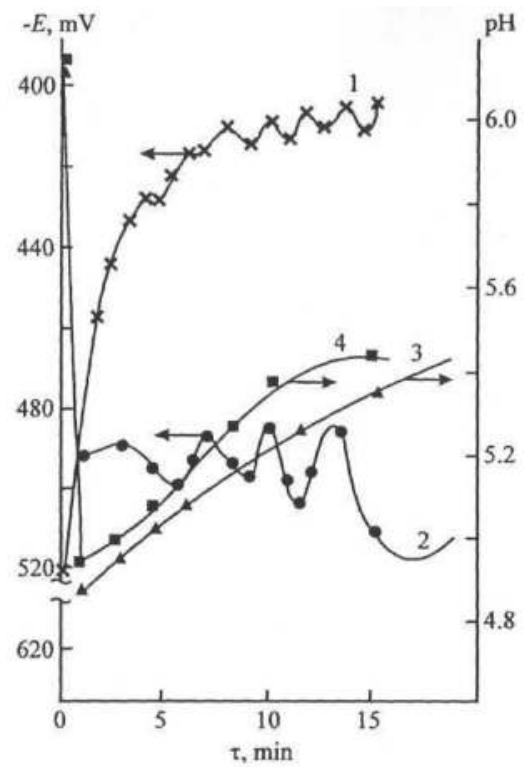

Fig. 6. Temperature dependencies of electrochemical potential $(1,2)$ and $\mathrm{pH}(3,4)$ at $20 \mathrm{~T}$ $(1,3)$ and $40^{\circ} \mathrm{C}(2,4) ; 0.01$ wt. $\% \mathrm{H}_{2} \mathrm{O}_{2}$.

(Figure 7.). These biomimetic sensors are distinguished by high hydrodynamic properties, operation stability and rapid speed of response. A tendency to an increase of the electrode potential is observed for biomimetic sensors, derived from catalase adsorbed on diasorb (without trypsine treatment), agarose (treated with trypsine and without it), and adhered to 
an aluminum electrode surface by $7.5 \%$ polyacrylamide gel. It is also observed for biomimetic sensors, derived from catalase adsorbed on diasorb (without trypsine treatment), $\mathrm{Si}_{2} \mathrm{O}_{3}$ (treated with trypsine and without it), and adhered to aluminum electrode surface by Pattex adhesive.

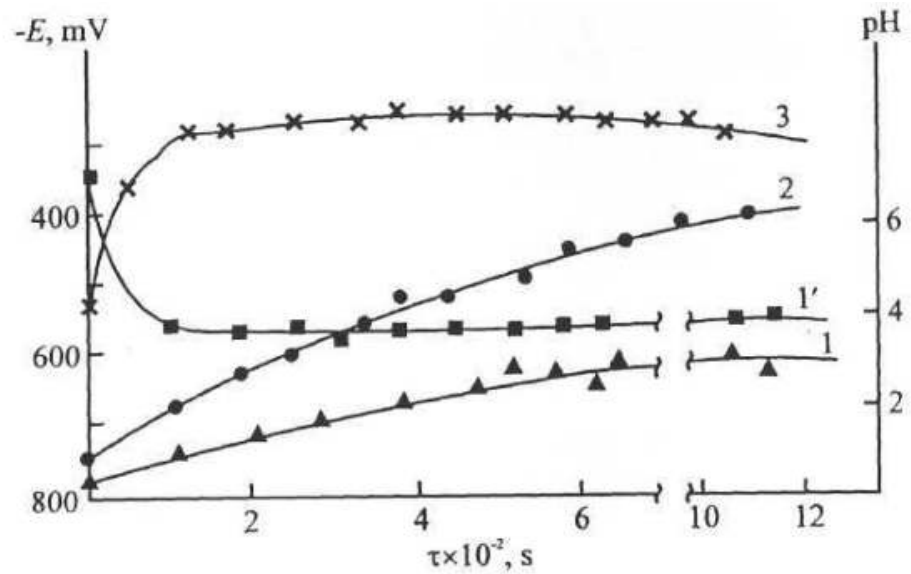

Fig. 7. Time dependencies of electrochemical potential (1-3) and $\mathrm{pH}$ of aqueous $\mathrm{H}_{2} \mathrm{O}_{2}\left(1^{\prime}\right)$ in the system. $T=20^{\circ} \mathrm{C}, 0.06$ wt. $\% \mathrm{H}_{2} \mathrm{O}_{2} .$. Catalase is adsorbed on diasorb $\left(1,1^{\prime}\right)$ or $\mathrm{A}_{2} \mathrm{O}_{3}(2,3)$, treated by trypsine and adhered to aluminum foil with $7.5 \%$ polyacrylamide gel $\left(1,1{ }^{\prime}, 2\right)$ or Pattex (3).

Biomimetic sensors, prepared by catalase adsorption on diasorb and agarose (treated with trypsine) and adhered to an aluminum electrode surface by Pattex adhesive, displayed an abrupt decrease of the electrode potential. Sensors prepared by catalase adsorption on $\mathrm{A}_{2} \mathrm{O}_{3}$ (without trypsine treatment) and adhesion to the aluminum electrode with Pattex adhesive displayed a high oscillation of the electrode potential, which induces extreme instability of the operation. Hence, it should be noted that sensor operation was always better in the case of enzyme treatment with trypsine.

When the carrier is selected, aluminum oxide should be preferred, because biomimetic sensors on it display higher characteristics (Figure 7). Moreover, they are low in price, long lived and stable, and possess high hydrodynamic properties.

Pattex adhesive combines well with such carriers as $\mathrm{AI}_{2} \mathrm{O}_{3}$ and $\mathrm{Si}_{2} \mathrm{O}_{3}$, but is absolutely useless for agarose and diasorb.

Thus, two reactions (catalase and electrochemical) are implemented in the biomimetic electrode $\mathrm{H}_{2} \mathrm{O}_{2} / \mathrm{Cl}^{-} / \mathrm{AgCl} / \mathrm{Ag}$ system. In the case of inorganic support, it is not the kinetic but the diffusion (external and internal) factor that is predominant, owing to which the electrochemical reaction is of a self-oscillation type $[7,8]$.

As can be seen from the data of Fig. 8, due to the presence of hydrogen peroxide in a water solution, the potential of the electrochemical system increased drastically at first in all cases because of the formation of a new surface layer on the electrode-solution boundary and then because of electrochemical reactions (1) and (2). After a certain period of time, an equilibrium surface layer formed, as indicated by the constant values of potentials on the electrode-solution and biomimetic electrode-solution boundaries. 


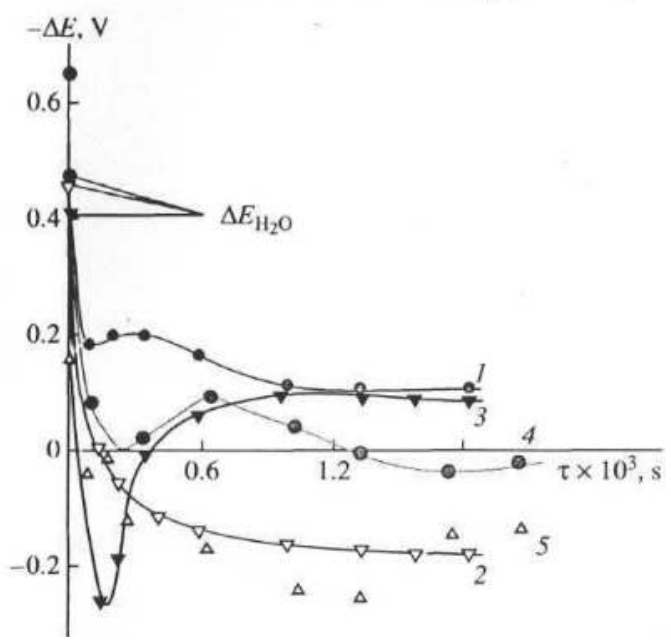

Fig. 8. Time dependences of the electrochemical potential $(\Delta E)$ in a reaction medium of $1 \%$ aqueous $\mathrm{H}_{2} \mathrm{O}_{2}$ at $22^{\circ} \mathrm{C}$ for electrodes prepared by the electrochemical procedure: (1) $\mathrm{Al}_{2} \mathrm{O}_{3} / \mathrm{Al}$; (2) hemin $\left(33.6 \mathrm{mg}\right.$ ) deposited by glueing on the surface of the $\mathrm{Al}_{2} \mathrm{O}_{3} / \mathrm{Al}$ electrode; (3) hemin (0.88 mg) and (4) and (5) TPhPFe(III) (0.084 and $0.44 \mathrm{mg}$, respectively) deposited by adsorption on the surface of the $\mathrm{A1}_{2} \mathrm{O}_{3} / \mathrm{AI}$ electrode.

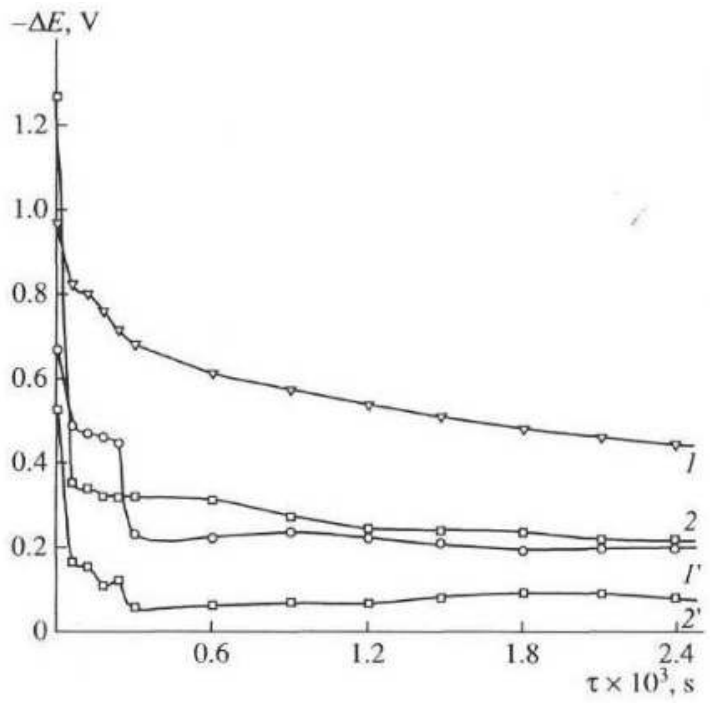

Fig. 9. Time dependences of the electrochemical potential $(\Delta E)$ in a reaction medium of $1 \%$ aqueous $\mathrm{H}_{2} \mathrm{O}_{2}$ at $22^{\circ} \mathrm{C}$ for electrodes prepared by the chemical procedure: $(1,2) \mathrm{Al}_{2} \mathrm{O}_{3} \mathrm{Al}$ electrodes prepared by the hydrothermal and aluminate methods, respectively; (1', 2') $\mathrm{TPhPFe}(\mathrm{III})$ ( 0.6 and $0.23 \mathrm{mg}$, respectively) deposited by adsorption on the surface of the $\mathrm{A}_{2} \mathrm{O}_{3} / \mathrm{A} 1$ electrode. 
As follows from curves 1 and 2, the electrochemical potential increased with time. After two sequential runs, the hemin selector prepared by the glue method was completely deactivated.

The tendency of curves 1 and 3 (Fig. 8) toward a constant value of $\Delta E$, identical for both, obviously showed that a catalase reaction was almost completely absent for curve 1 and vanished after $600 \mathrm{~s}$ for 3 . Moreover, the reproducibility of results and the activity of the electrode prepared by adsorption did not change after all experiments.

Irrespective of the amount of the deposited working element, biomimetic electrodes with TPhPFe(III) (curves 4 and 5, Fig. 8) also had a long lifetime, and their activity was almost independent of the number of experiments. As follows from the values of $\Delta E$ on curves 4 and 5, they depend considerably on the amount of TPhPFe(III) deposited on $\mathrm{A}_{2} \mathrm{O}_{3} / \mathrm{A} 1$. The hemin biomimetic electrode was more active than TPhPFe(III), but the latter was much more stable after prolonged service [9].

Figure 9 shows the catalase activities of biomimetic electrodes (the $\mathrm{A}_{2} \mathrm{O}_{3} / \mathrm{A} 1$ electrode was prepared by a chemical procedure under the same conditions as in the previous experiment).

As can be seen from Fig. 9, the presence of $\mathrm{H}_{2} \mathrm{O}_{2}$ in the system always leads to an increase in the electrochemical potential of the system.

The amount of TPhPFe(III) deposited by hydrothermal processing of the surface in the presence of hydrogen peroxide was higher than the amount of the compound deposited by the aluminate method, but the catalytic activity of the latter was appreciably higher. This indicates that the deposition procedure plays an important role.

The electrode prepared by the aluminate method was most stable and sensitive, although the active surface layer was slightly destroyed during both experiments.

A comparison of the data in Figs. 8 and 9 shows that electrodes prepared by the chemical method were inferior, in catalase activity and stability, to biomimetic electrodes prepared by the electrochemical procedure.

The electrodes prepared by the electrochemical method have a limiting sensitivity to the concentration of $\mathrm{H}_{2} \mathrm{O}_{2}, 10^{-2}$ wt \%, while the electrodes obtained by the chemical procedure showed activity in the vibrational mode probably because of diffusion (their sensitivity was $10^{-6}$ wt \%, $\mathrm{H}_{2} \mathrm{O}_{2}$ ).

Note that the electrodes prepared by the chemical technique proved rather sensitive, but they were much less stable than the electrodes obtained by the electrochemical method.

The supposed electrochemical mechanism of the catalase reaction was stepwise (Fig. 10), as noted in [6, 7]. At the first stage, highly active hydroperoxide particles formed, which were responsible for the transfer of electrons from the cathode to the iron ion and their subsequent distribution. As a result, at the last stage, hydroxide anions were generated to the volume (reaction medium) with concurrent regeneration of the biomimetic. This mechanism shows how $\mathrm{pH}$ in the electrochemical system becomes higher than in bidistilled water ( $\mathrm{pH}$ 6.2).

As a result, catalase and electrochemical reactions proceed consecutively in the system. These reactions can be represented as

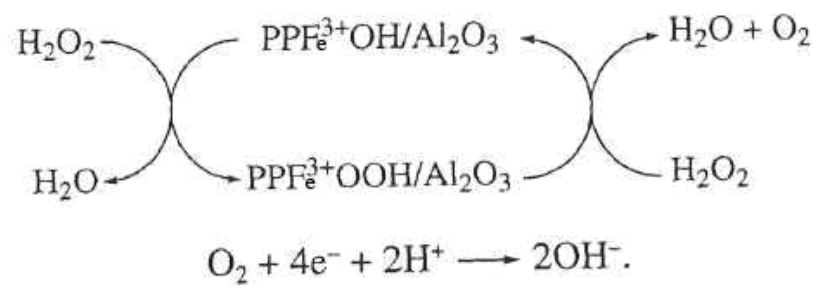




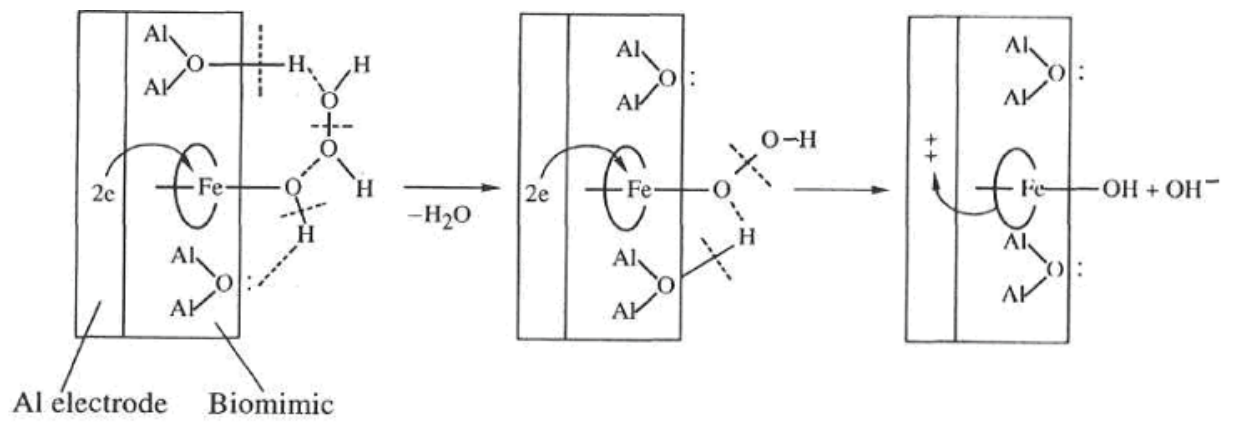

Fig. 10. Mechanism of the decomposition of $\mathrm{H}_{2} \mathrm{O}_{2}$ on the catalase biomimic electrode.

\section{Peroxidase biomimetic sensors}

The peroxidase-mimetic electrode was studied in the following way. First, the potential of twice distilled water (base solution) was measured. Then, the required amount of $\mathrm{C}_{2} \mathrm{H}_{5} \mathrm{OH}$ was added and the variation of the electrode potential was recorded. Next a certain amount of $\mathrm{H}_{2} \mathrm{O}_{2}$ (oxidizer) was introduced into the solution and the potential shift was measured. The potential of the electrochemical system changed as a result of synchronous reactions (catalase and peroxidase) that occurred in the system.

As in $[3,4]$, the choice of the electrode was dictated by the availability and low cost of the material and by the fact that it is inert with respect to $\mathrm{H}_{2} \mathrm{O}_{2}$. A magnetic stirrer was employed in all experiments.

The ethanol concentration was varied from $10^{-8}$ to 5 wt \% while the hydrogen peroxide concentration remained unchanged ( $1 \mathrm{wt} \%)$. The results are displayed in Fig. 11, where the potential curve of twice distilled water is also given for comparison. According to $[7,8]$ the electrochemical reaction environment possesses catalase activity. For this reason, Fig 11 also shows the curve of the electrochemical potential shift of $1 \%$ aqueous solution of $\mathrm{H}_{2} \mathrm{O}_{2}$ in the absence of $\mathrm{C}_{2} \mathrm{H}_{5} \mathrm{OH}$.

To examine the curves of the peroxidase reaction, it was necessary to measure the electrochemical potential of a $1 \%$ aqueous solution of ethanol. Its value fully coincides with the potentials of twice distilled water. It follows that the water-alcohol solution virtually remains inert with respect to the electrode. The peroxidase curves (Fig. 11) describing the potential shift of the reactive mixture $\mathrm{C}_{2} \mathrm{H}_{5} \mathrm{OH}+\mathrm{H}_{2} \mathrm{O}_{2}$ under conditions when the value of $\left[\mathrm{H}_{2} \mathrm{O}_{2}\right]$ is maintained unchanged $(1 \mathrm{wt} \%)$ while $\left[\mathrm{C}_{2} \mathrm{H}_{5} \mathrm{OH}\right]$ is varied from $10^{-6}$ to $5 \mathrm{wt} \%$, show a more substantial potential shift to the positive side than the catalase curves of $\mathrm{H}_{2} \mathrm{O}_{2}$. The highest difference between the potentials of $\mathrm{H}_{2} \mathrm{O}_{2}$ and the $\mathrm{C}_{2} \mathrm{H}_{5} \mathrm{OH}+\mathrm{H}_{2} \mathrm{O}_{2}$ mixture is observed at $\tau=10 \mathrm{~s}$. For $1 \%$ solutions of $\mathrm{H}_{2} \mathrm{O}_{2}$ and $\mathrm{C}_{2} \mathrm{H}_{5} \mathrm{OH}, \Delta \mathrm{E}=0.2 \mathrm{~V}$. In virtually all the experiments, the potentials measured in the initial period of the peroxidase reaction are also higher than those at later periods of the reaction. Note that the potential of the $\mathrm{C}_{2} \mathrm{H}_{5} \mathrm{OH}+$ $\mathrm{H}_{2} \mathrm{O}_{2}$ mixture never coincided with that of $\mathrm{H}_{2} \mathrm{O}_{2}$ and was never below it. Thus, a very important conclusion can be derived: a reaction between $\mathrm{C}_{2} \mathrm{H}_{5} \mathrm{OH}$ and $\mathrm{H}_{2} \mathrm{O}_{2}$ undoubtedly occurs in the system; this reaction is responsible for an increase in the potential of the peroxidase reaction, the increase being higher than that for the catalase reaction. In the absence of the peroxidase reaction, the system potential would coincide with the potential of the catalase reaction. The curves of peroxidase potentials are, however, arranged relative to 
each other in such a manner that a certain periodicity in the dependence of peroxidase reaction potentials on the low concentrations of $\mathrm{C}_{2} \mathrm{H}_{5} \mathrm{OH}$ can be detected. This arrangement may be attributed to the inadequate procedure of the fixation of the peroxidase mimetic on the surface of the aluminum electrode. This problem can presumably be solved by eliminating possible systematic errors involved in the preparation of the biomimetic electrode.

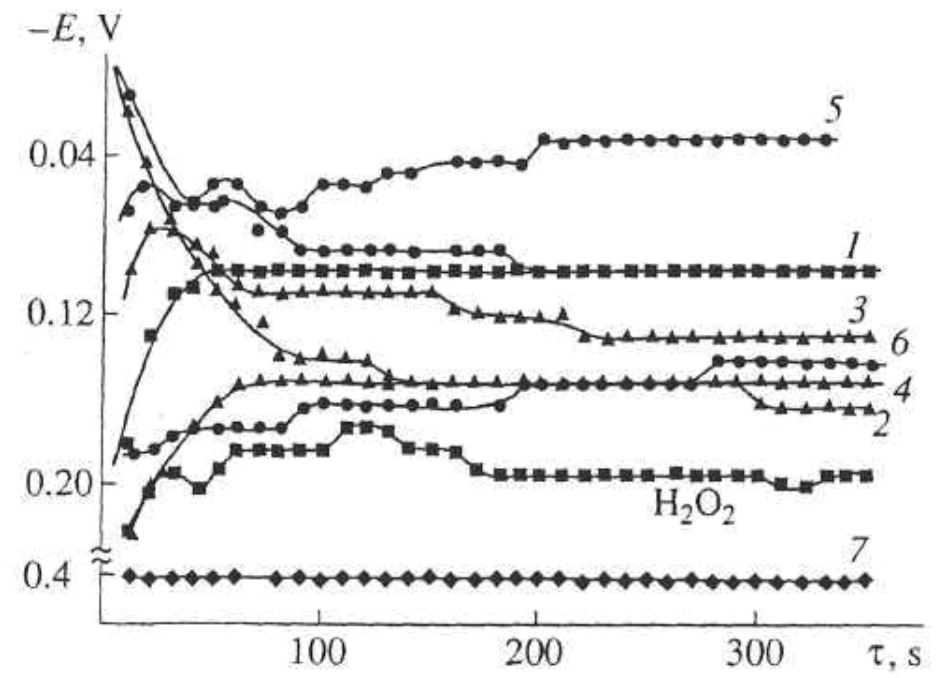

Fig. 11. Time dependences of the electrochemical potential at 1 wt $\% \mathrm{H}_{2} \mathrm{O}_{2}$ and various concentrations of $\mathrm{C}_{2} \mathrm{H}_{5} \mathrm{OH}$ : (1) $5 \times 10^{-6}$, (2) $5 \times 10^{-5}$, (3) $5 \times 10^{-4}$, (4) $5 \times 10^{-2}$, (5) $5 \times 10^{-1}$, and (6) $5 \mathrm{wt} \%$; (7) twice distilled water.

It is well known that acetaldehyde in the $\mathrm{C}_{2} \mathrm{H}_{5} \mathrm{OH}+\mathrm{H}_{2} \mathrm{O}_{2}$ system can appear not only as a result of a peroxidase reaction in the presence of a catalyst, but also by the monooxygenase mechanism. To solve this problem, we used the standard method of identification of the peroxidase reaction [10]. For this purpose, we added the indicator thymolphthalein to a $1 \%$ aqueous solution of $\mathrm{H}_{2} \mathrm{O}_{2}$ containing a biosimulator sample and identified the peroxidase mechanism of acetaldehyde formation by monitoring how the color of the solution changes from colorless to dark blue.

Another series of experiments was undertaken to study the effect of the product of peroxidase reaction (acetaldehyde) on the electrochemical potential of the system.

Figure 12 (curve 3) shows that the electrochemical potential of acetaldehyde is belower than the potential of water and ethyl alcohol (acetaldehyde is a nonpolar compound). The curve 1 of the potential shift for the $\mathrm{CH}_{3} \mathrm{CHO}+\mathrm{H}_{2} \mathrm{O}_{2}$ reactive mixture is higher than that for hydrogen peroxide. This suggests that a reaction (presumably .involving monooxygenase) occurs between $\mathrm{H}_{2} \mathrm{O}_{2}$ and $\mathrm{CH}_{3} \mathrm{CHO}$ to yield a more polar compound $\left(\mathrm{CH}_{3} \mathrm{COOH}\right)$.

The experimental data presented in Fig. 12, curve 2 were obtained in the following manner. An aqueous solution of $\mathrm{H}_{2} \mathrm{O}_{2}$ was introduced into the $\mathrm{C}_{2} \mathrm{H}_{5} \mathrm{OH}+\mathrm{CH}_{3} \mathrm{CHO}$ reactive mixture at $\tau=130 \mathrm{~s}$. In the segment of curve 2, the potential of aqueous $\mathrm{C}_{2} \mathrm{H}_{5} \mathrm{OH}$ and $\mathrm{CH}_{3} \mathrm{CHO}$ (up to $\mathrm{T}=130 \mathrm{~s}$ ) is noticeably higher than that for each of these compounds, which are usually at 
the level of the water potential or lower. This phenomenon may be attributed to the formation of a new surface layer on the electrode. If $\mathrm{C}_{2} \mathrm{H}_{5} \mathrm{OH}$ and $\mathrm{CH}_{3} \mathrm{CHO}$ separately formed the electrode surface, curve 2 (Fig. 12) with a characteristic segment up to $\tau=130 \mathrm{~s}$ would hardly be obtained. Ethanol evidently reacts in water with acetaldehyde to yield associates whose activity is higher than that of each of them. Introduction of $\mathrm{H}_{2} \mathrm{O}_{2}$ into the $\mathrm{C}_{2} \mathrm{H}_{5} \mathrm{OH}+\mathrm{CH}_{3} \mathrm{CHO}$ mixture at $\tau=130$ s produces a sufficient jump in the potential with the formation of maxima and minima, which is typical of complex electrochemical reactions. We may presume the presence of acetaldehyde molecules in two states in the reaction system. One of the states is produced in the peroxidase reaction and exists at the electrode surface or in the surface layer, in which $\mathrm{CH}_{3} \mathrm{CHO}$ concentration is higher than in the bulk. The other state is produced when $\mathrm{CH}_{3} \mathrm{CHO}$ is in the reaction volume. We believe that a combination of these two states is responsible for the observed maxima and minima in curve 2, Fig. 12.

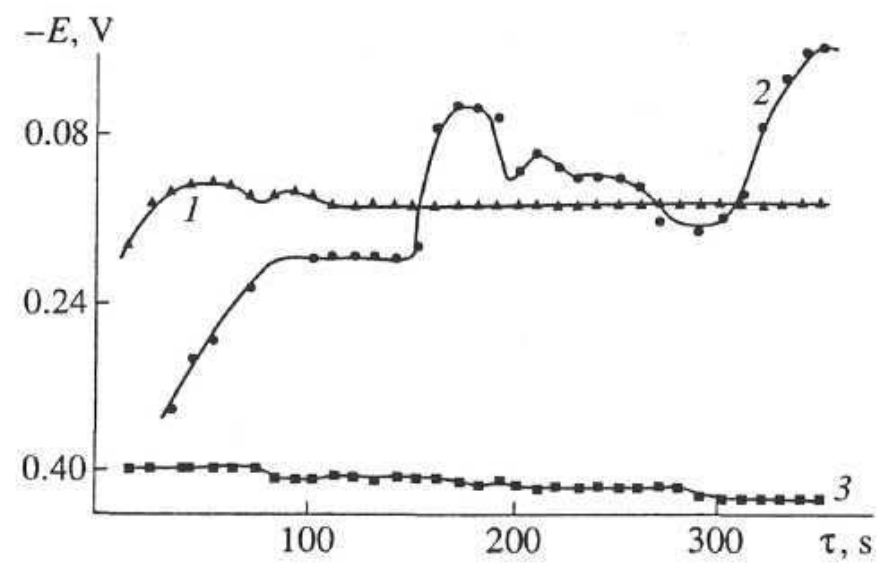

Fig. 12. Time dependences of the potential of the peroxidase electrode at $1 \mathrm{wt} \% \mathrm{H}_{2} \mathrm{O}_{2}$ and various concentrations of the product of the electrochemical reaction $\left(\mathrm{CH}_{3} \mathrm{CHO}\right)$ : (1) 0.25 , (2) $0.25 \cdot 10^{-2} \mathrm{wt} \% \mathrm{C}_{2} \mathrm{H}_{5} \mathrm{OH}$, and (3) $0.025 \%$.

The peroxidase reaction, which is synchronous with the catalase reaction, also occurs in the studied electrochemical system. Both reactions interact (are conjugate) with each other via the common intermediate $\mathrm{PPFe}{ }^{3+} \mathrm{OOH} / \mathrm{Al}_{2} \mathrm{O}_{3}$.

It consists of several elementary stages displayed in Fig. 10. The first stage yields the highly active hydroperoxide species, which is responsible for the electron transfer from the cathode to the iron ion followed by their further redistribution. As a result, at the last stage in the bulk (reaction environment), hydroxide anions are generated with simultaneous regeneration of a biomimetic. This mechanism convincingly shows how the $\mathrm{pH}$ value in the system becomes higher than that for twice distilled water $(\mathrm{pH} 6.2)[7,8]$.

The proposed mechanism of peroxidase reaction was considered by analogy with the mechanism of the catalase reaction (Fig. 13). Note that a proton transferred to the active site of the biomimetic electrode can be replaced by $\mathrm{H}^{+}$from the bulk of the reaction environment. The mechanisms of catalase and peroxidase reactions give us ideas about the pathways of their implementation in the electrochemical regime. The ratio of the products of 
both reactions $\left(\mathrm{O}_{2}\right.$ and $\left.\mathrm{CH}_{3} \mathrm{CHO}\right)$ depends on the ratio of the rates of the interaction of $\mathrm{H}_{2} \mathrm{O}_{2}$ and $\mathrm{CH}_{3} \mathrm{CHO}$ with the surface intermediate.

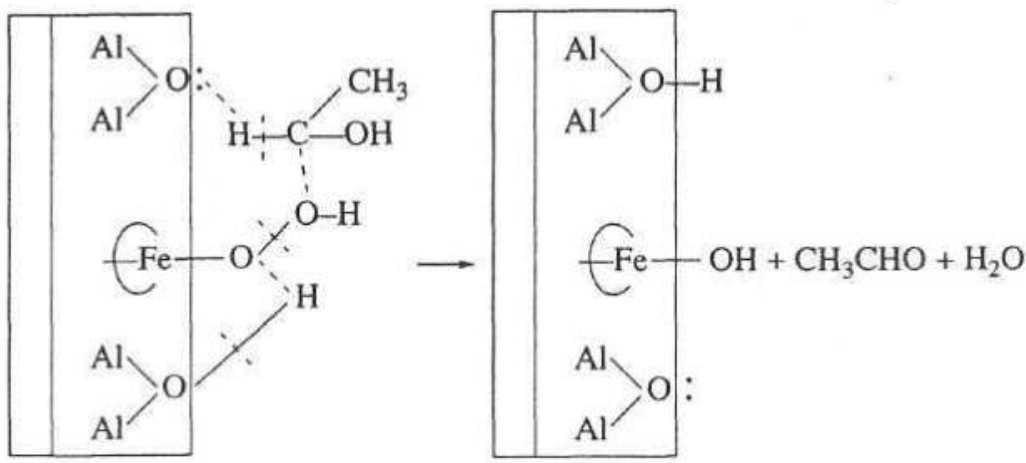

Fig. 13. Suggested mechanism of operation of the peroxidase-mimetic electrode under electrocatalytic conditions.

The schemes shown in Fig 10. explain the coherent and simultaneous mechanism of catalase and peroxidase reactions, which can be represented as [1]

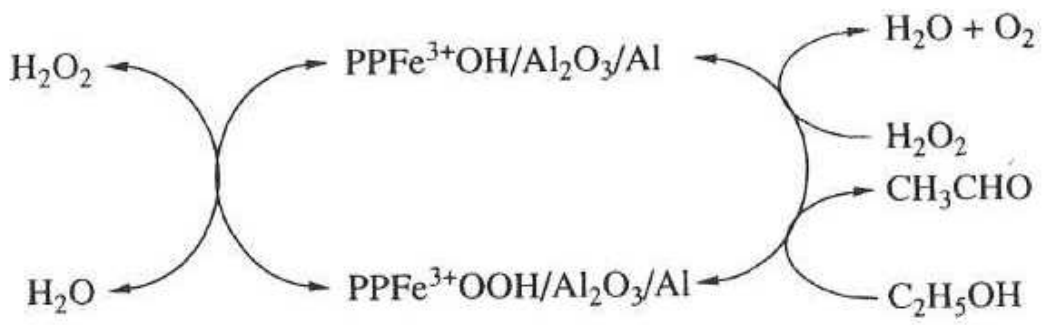

For comparison, we give the results of experiments with biomimetic electrodes prepared by the chemical method under the identical conditions.

Note that the electrodes prepared in different ways proved stable against the action of the oxidant.

In another series of experiments, we determined the lowest (threshold) sensitivity of the system to ethanol. Biomimetic electrodes with TPhPFe(III) made it possible to detect ethanol in an amount of $10^{-6} \mathrm{wt} \%$ in an aqueous solution, while the stability of the electrode remained high.

Figure 14 presents the results of experiments in which $\mathrm{H}_{2} \mathrm{O}_{2}$ concentration was varied from 0.01 to $1 \mathrm{wt} \%$ for constant $\mathrm{C}_{2} \mathrm{H}_{5} \mathrm{OH}$ concentration ( $\left.1 \mathrm{wt} \%\right)$. It can readily be seen that the electrode potential of the $\mathrm{C}_{2} \mathrm{H}_{5} \mathrm{OH}+\mathrm{H}_{2} \mathrm{O}_{2}$ reactive mixture grows as $\mathrm{H}_{2} \mathrm{O}_{2}$ concentration increases. This is associated with the fact that the growth of the $\mathrm{H}_{2} \mathrm{O}_{2}$ concentration leads to an increase in the rates of all three reactions considered above. The observed complex pattern of the curves of the potential shift and the scatter of the experimental data can presumably be attributed to the fact that, when the biomimetic electrode is made using a gluing material, the active mass is deposited nonuniformly in thickness. 
The experimental data involved in the determination of the sensitivity threshold of the elaborated peroxidase-mimetic sensor for the analysis of $\mathrm{C}_{2} \mathrm{H}_{5} \mathrm{OH}$ traces are given in Fig. 15 . The electrode potentials in Fig. 15 correspond to various $\mathrm{C}_{2} \mathrm{H}_{5} \mathrm{OH}$ traces and are the best values of $\Delta E$ selected from the experimental curves in Fig. 11. Note that the entire experimental material is obtained on one model of an aluminum electrode. Each time a new peroxidase-mimetic electrode was prepared, we mechanically scraped off the depleted peroxidase mimetic from its surface and then deposited a fresh portion of it with glue. This procedure for the preparation of a biomimetic electrode may be a source of systematic errors. For example, the aluminum electrode itself may be worn out. Moreover, we have no assurance that the spent material is completely removed from the electrode surface. For this reason, the alternation of maxima and minima in Fig. 15 may be due to both the systematic errors involved in the preparation of biomimetic electrodes and the complex nature of the physicochemical processes that occur on the electrode surface.

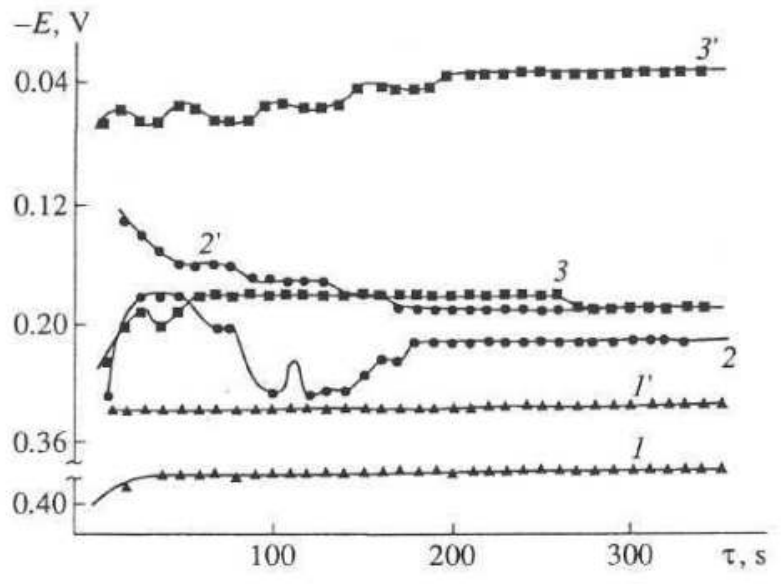

Fig. 14. Dependences of the potentials of (1-3) catalase and ( $\left.1^{\prime}-3^{\prime}\right)$ peroxidase reactions on the concentration of $\mathrm{H}_{2} \mathrm{O}_{2}$ in a mixture at 1 wt \% $\mathrm{C}_{2} \mathrm{H}_{5} \mathrm{OH}$; $\left(1,1^{\prime}\right) 0.01,\left(2,2^{\prime}\right) 0.1,\left(3,3^{\prime}\right) 1$ wt \% $\mathrm{H}_{2} \mathrm{O}_{2}$. 
We verified some of these suppositions by an experiment with a peroxidase-mimetic sensor made on a new aluminum electrode under the conditions corresponding to one of the minima in the curve displayed in Fig. 15. The result of this experiment is shown in Fig. 15 as a separate point $A$. It follows that the minimum observed at a $\mathrm{C}_{2} \mathrm{H}_{5} \mathrm{OH}$ concentration of $10^{-3}$ wt \% depends on the state of aluminum foil: the fresh electrode shows a sharp jump of the potential to the positive side. This effect suggests how the physicochemical properties of the proposed biomimetic sensor and the technique of preparation of biomimetic electrodes can be improved. The data in Fig. 15 show that the sensitivity threshold of the elaborated sensor with respect to ethanol in aqueous solutions is $10^{-8} \mathrm{wt} \%$.

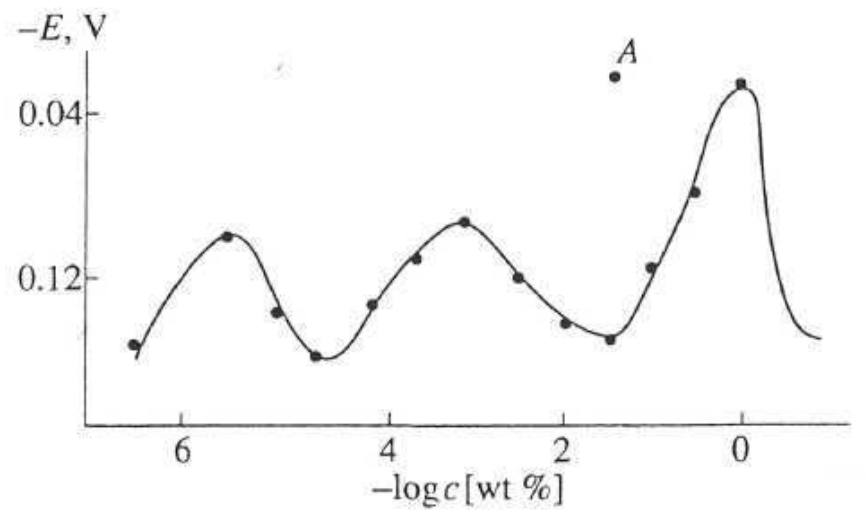

Fig. 15. Potential of the peroxidase sensor as a function of ethanol concentration (c) in an aqueous solution at $0.01 \mathrm{wt} \% \mathrm{H}_{2} \mathrm{O}_{2} ; A$ is the result obtained on a new aluminum electrode.

\section{Conclusion}

As a result of our studies, we developed biomimetic electrodes that did not lose their activity for prolonged periods of time under the action of the oxidant and its intermediates and final products of the decomposition of $\mathrm{H}_{2} \mathrm{O}_{2}$ and oxidation of $\mathrm{C}_{2} \mathrm{H}_{5} \mathrm{OH}$.

The designed biomimetic sensors proved stable, due to which they could be reused many times.

\section{Reference}

[1] Nagiev T.M., Coherent Synchronized Oxidation Reactions by Hydrogen Peroxide. Elsevier. Amsterdam. 2007. 325 p.

[2] T.M. Nagiev, Russian Journal of Physical Chemistry, Vol. 70, No. 6, 1996, pp. 895 - 903.

[3] Sorochinsky, V.V. and Kurganov, B.I., Prikl. Biokhim. MikrobioL, 1997, Vol. 33, No. 6, p. 579 (in Russian).

[4] Glazkov, V.V., Mizgunov, U.M., Zolotova, G.A. and Dolmanova, I.F., Zh. Analit. Khim., 1997, Vol. 52, No. 1, p. 83 (in Russian).

[5] Varfolomeev, S.D., Kurichkin, I.N. and Aropolov A.I., 1996, Vol. 11, No. 9, pp. 863-871. 
[6] Nagiev, T.M., Abbasova, M.T., Baba-zade, S.N., Kuliev, S.A., Stepanova, E.V. and Agamamedova, L.M., J. Appl. Biochem. Biotechnol, 2000, Vol. 88, p. 275.

[7] T.M. Nagiev, M.T. Abbasova, S.N. Baba-zade, E.V. Stepanova and L.M. Agamamedova, Russian Journal of Physical Chemistry, Vol. 73, No. 12, 1999, pp. 2032-2036.

[8] L.M. Agamamedova, M.T. Abbasova and T.M. Nagiev, Russian Journal of Physical Chemistry, Vol. 76, No. 12, 2002, pp. 1993-1997.

[9] T.M. Nagiev, N.A. Sardarly, Russian Journal of Physical Chemistry, 2008, vol. 83, No 8, pp. 1400-1404.

[10] Waker, J.F., Formaldehyde, Goskomkhimizdat, Moscow, 1957, 423 p. (in Russian). 


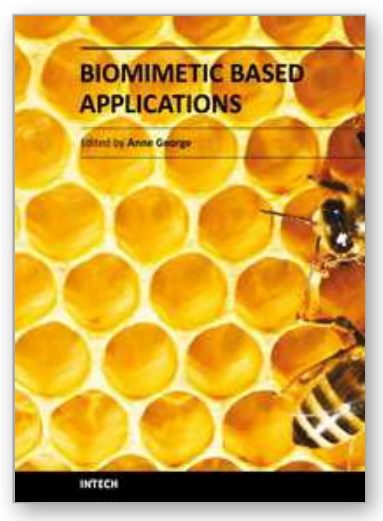

\author{
Biomimetic Based Applications \\ Edited by Prof. Marko Cavrak
}

ISBN 978-953-307-195-4

Hard cover, 572 pages

Publisher InTech

Published online 26, April, 2011

Published in print edition April, 2011

The interaction between cells, tissues and biomaterial surfaces are the highlights of the book "Biomimetic Based Applications". In this regard the effect of nanostructures and nanotopographies and their effect on the development of a new generation of biomaterials including advanced multifunctional scaffolds for tissue engineering are discussed. The 2 volumes contain articles that cover a wide spectrum of subject matter such as different aspects of the development of scaffolds and coatings with enhanced performance and bioactivity, including investigations of material surface-cell interactions.

\title{
How to reference
}

In order to correctly reference this scholarly work, feel free to copy and paste the following:

T.M.Nagiev (2011). Physicochemical Peculiarities of Iron Porphyrin - Containing Electrodes in Catalase - and Peroxidase - Type Biomimetic Sensors, Biomimetic Based Applications, Prof. Marko Cavrak (Ed.), ISBN: 978953-307-195-4, InTech, Available from: http://www.intechopen.com/books/biomimetic-basedapplications/physicochemical-peculiarities-of-iron-porphyrin-containing-electrodes-in-catalase-and-peroxidasetyp

\section{INTECH}

open science | open minds

\section{InTech Europe}

University Campus STeP Ri Slavka Krautzeka 83/A 51000 Rijeka, Croatia Phone: +385 (51) 770447

Fax: +385 (51) 686166 www.intechopen.com

\section{InTech China}

Unit 405, Office Block, Hotel Equatorial Shanghai No.65, Yan An Road (West), Shanghai, 200040, China 中国上海市延安西路65号上海国际贵都大饭店办公楼 405 单元 Phone: +86-21-62489820

Fax: $+86-21-62489821$ 
(C) 2011 The Author(s). Licensee IntechOpen. This chapter is distributed under the terms of the Creative Commons Attribution-NonCommercialShareAlike-3.0 License, which permits use, distribution and reproduction for non-commercial purposes, provided the original is properly cited and derivative works building on this content are distributed under the same license. 